\title{
Home-Based Mirror Therapy with Individual Set of Exercises Improves Phantom Limb Pain and Phantom Limb Sensation of Lower Extremity Amputees
}

\author{
Hung Do Phuoc* and Chung Huynh Thanh \\ Department of Orthopaedics and Rehabilitation, University of Medicine and Pharmacy at Ho Chi Minh City, Vietnam \\ *Corresponding author: Hung Do Phuoc, Department of Orthopaedics and Rehabilitation, University of Medicine and \\ Pharmacy at Ho Chi Minh City, Vietnam
}

\section{ARTICLE INFO}

Received: 幽 July 06, 2021

Published: 慧 July 15, 2021

Citation: Hung Do Phuoc, Chung Huynh Thanh. Home-Based Mirror Therapy with Individual Set of Exercises Improves Phantom Limb Pain and Phantom Limb Sensation of Lower Extremity Amputees. Biomed J Sci \& Tech Res 37(2)-2021. BJSTR. MS.ID.005966.

Abbreviations: PLPh: Phantom Limb Phenomenon; PLP: Phantom Limb Pain; CESD: Center for Epidemiologic Studies Depression; TMR: Targeted Muscle Reinnervation; MT: Mirror Therapy; rTMS: Repetitive Transcranial Magnetic Stimulation; EMDR: Eye Movement Desensitization And Reprocessing; PLS: Phantom Limb Sensation; TDTEP: Total Daily Time Experiencing Pain

\begin{abstract}
Background: The phantom limb phenomenon (PLP) usually occurs after a lower limb amputation with the rate about $85 \%$. Mirror therapy is considered a safety, economical and effective procedure in the treatment of PLP.

Objectives: To identify the improvement of PLP and depression condition of lower limb amputees by home-based mirror therapy with individual set of exercises

Methods: The lower limb amputees suffering PLP that did not reduced after a month after amputation were recruited. Each patient was trained a set of exercises which was based on his/her preference. He/ she would practice the set at home with an individual mirror for 4 weeks. The patients were scored the intensity of pain (by VAS) and noted the total daily time experiencing pain and pain killer before and after finishing the therapy program. CESD was used to assess depression
\end{abstract}

Results: From January 2020 to August 2020 We conducted a pilot study with 20 patients, most of them were men $(90 \%)$.The main cause of amputation was trauma (80\%). The duration and intensity of phantom limb pain or phantom limb sensation significantly reduced after the interval of performing home-based mirror therapy. The CESD score remarkably dipped after a month $(p<0.05)$. The effectiveness continued to be improve or stable at the end of the study.

Conclusion: Mirror therapy should be applied soon to amputees after amputation of the lower limb.

Keywords: Mirror Therapy; Phantom Limb Phenomenon

\section{Introduction}

Lower limb amputation could be the final decision to solve uncurable disorders due to trauma, infection and other general diseases [1,2]. However, the amputees might suffer lasting phantom limb phenomenon (PLPh) (including phantom limb pain (PLP) and phantom limb sensation PLS [3]) with many negative impacts on their life such as the increasing demand of pain killer, depression and impairment of daily activities and social functions [4]. The rate of PLPh is about $85 \%[5,6]$. A study found that more than $50 \%$ of patients with PLP suffered daily pain with the significant intensity rated from moderate to severe [7]. The treatment mainly includes three main groups: pharmacology, non-pharmacology and surgery.

Each approach has its own advantages and disadvantages relating to complications and cost benefit. Recently, mirror therapy is emerging and considered as a safe, economic and effective procedure in treatment of PLPh [9-11], although it was first used by Ramachandran VS in 1996 [8]. By placing a mirror parasagittally between the arms or legs and viewing the reflected movements of the intact limb while attempting simultaneous movements with 
the phantom limb, the intention is that the patient perceives the reflection to be their amputated limb. This phenomenon possibly addresses incongruence between proprioceptive and visual inputs caused by cortical reorganization. Currently, the method is improved with many kinds of exercises so that the patients could do at home by themselves. However, one of the key for success is to select the appropriate exercise for individual.

\section{Objectives}

Our study was designed to investigate the improvement of PLP and depression after home-based mirror therapy with personalized exercises for lower limb amputee amputation.

\section{Methods}

We conducted the study with any patient who did not reduced the PLP symptoms after a month of surgery

\section{Criteria}

\section{Inclusion Criteria}

a) Unilateral lower limb amputation

b) Phantom limb pain score (40-100 on VAS)

c) Either gender.

\section{Exclusion Criteria}

a) Amputees with psychological/neurological impairments.

b) Amputees having neuropathic pain other than phantom limb pain.

c) Patients having visual-spatial impairments.

d) Patients having residual limb pain.

e) Inability to give informed consent.

f) Infectious stump

g) Severe hearing loss h) Any condition that restricts the movement of opposite limb, pain or limited range of motion in the intact limb

i) Infectious and systematic diseases.

\section{Research Design}

Case -Series Study

\section{Procedures}

The patients were initially recorded information and assessed about pain with VAS and their use of pain killer and depression with CESD(Center for Epidemiologic Studies Depression Scale. Each patient also received an appropriate mirror and a booklet that contains guides of basic eleven exercises. In general, the exercise program was based on Netherlands guidelines [12] and the Ministry of Health's guidelines on mirror therapy for PLPh [13] and included three groups: facilitation of visual illusion, sensory exercises, and basic motor exercises. However, each patient had individual exercises according to their preferences. The patients were asked to try every exercise, note which one made them comfortable and select at least one exercise of each group. That meant each patient had a personal set of exercise.

In this study, we used a 3mm thick acrylic glass with a cushion and a wooden frame to enhance its stability and prevent the injuries caused by the edge of the mirror. It had the enough length and width so that the reflection of the normal legs during exercise was complete and clear in the mirror (Figure 1). We recommended they would finish their set twice a day, at least 15 minutes per one time. The investigator would perform video call to check their adherence every two days of the first week and then once a week for 3 weeks. After finishing the one month program, the patients would be reassessed.

\section{Data Analysis}

All analytical procedures use Stata 14.2 software.
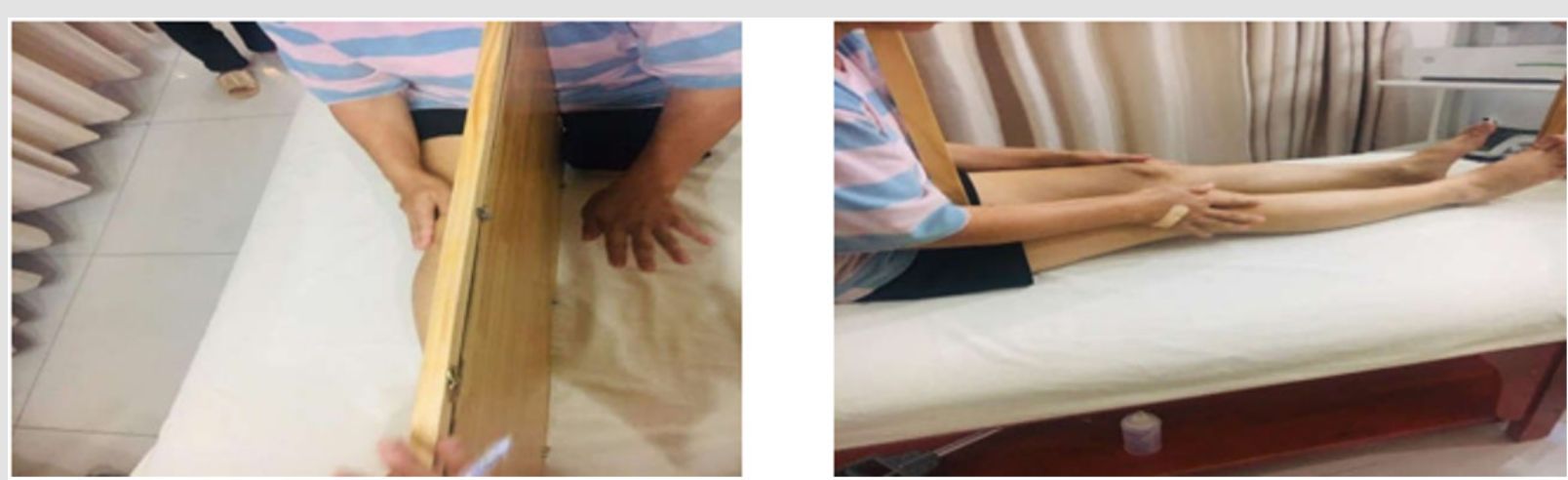

Figure 1: Exercises with mirror (Source: Actual pictures). 


\section{Results}

20 patients were recruited in the study from January 2020 to August 2020 at HCMC Hospital for Rehabilitation and Occupational Diseases. More than half of them were 35 years or older (55\%). Male was the majority (90\%). The cause of amputation mainly was trauma. The level of amputation around knee was met in $60 \%$ (Table 1A). The point of time to start the mirror therapy was about 35.5 days after amputation. The average follow-up time was 4 months. The pain characteristics were illustrated in Table 1B. The chief complain was both phantom limb pain(PLP) and phantom limb sensation (PLS). Its onset appeared rather soon from 1 to 3 days after amputation. The pain intensity was significant from moderate to severe. The sorrow lasted long with 150 minutes per day in average (Table 2). The depression condition was illustrated in Table 3. Two third of patients had signs and symptoms of depression with CESD more than 16.19/20 patients demonstrated their adherence at the time of call. One half said they could finished all the exercises with interesting;nearly50\% did not prefer Hip abduction and adduction, picking up gravel with toes into a cup and writing letters with your feet in the air (Table 2).

Table 1A: Demographic of the patients $(n=20)$.

\begin{tabular}{|c|c|c|}
\hline Characteristics & Frequency & Ratio (\%) \\
\hline \multicolumn{3}{|c|}{ Age Group } \\
\hline 18 - 34 years old & 9 & 45 \\
\hline$\geq 35$ years old & 11 & 55 \\
\hline \multicolumn{3}{|c|}{ Gender } \\
\hline Male & 18 & 90 \\
\hline Female & 2 & 10 \\
\hline \multicolumn{3}{|c|}{ Causes Leading to Amputation } \\
\hline Trauma & 16 & 80 \\
\hline Diabetes & 2 & 10 \\
\hline Infections & 1 & 5 \\
\hline Blood vessel & 1 & 5 \\
\hline \multicolumn{3}{|c|}{ Amputation Level } \\
\hline Foot & 5 & 25 \\
\hline Ankle & 1 & 5 \\
\hline Below knee & 5 & 25 \\
\hline Above knee & 7 & 35 \\
\hline Hip disarticulation & 1 & 5 \\
\hline Hemipelvectomy & 1 & 5 \\
\hline
\end{tabular}

Table 1B: Pain characteristics.

\begin{tabular}{|c|c|c|}
\hline \multicolumn{3}{|c|}{ PLPh Type } \\
\hline PLP & 11 & 55,0 \\
\hline PLS & 9 & 45,0 \\
\hline \multicolumn{3}{|c|}{ Onset of PLPh after Amputation } \\
\hline PLP & $2(1-3)$ days & \\
\hline PLS & $2(1-3)$ days & \\
\hline \multicolumn{3}{|c|}{ Follow-Up Time after Training } \\
\hline PLP & $4(4-5)$ months & \\
\hline PLS & $4(3-4)$ months \\
\hline
\end{tabular}

Table 2: The patient's preference of exercise.

\begin{tabular}{|c|c|c|}
\hline Exercise & n & Ratio(\%) \\
\hline Toe flexion and extension & 20 & 100 \\
\hline Ankle flexion and extension & 20 & 100 \\
\hline Ankle rotation & 20 & 100 \\
\hline Knee flexion and extension & 20 & 100 \\
\hline Hip abduction and adduction & 11 & 55 \\
\hline Rolling foot on a tennis ball & 20 & 100 \\
\hline Scratching sole with long scrub & 20 & 100 \\
\hline Touching leg with finger & 20 & 100 \\
\hline Touching leg with palm & 20 & 100 \\
\hline Picking up gravel with toes into a cup & 12 & 60 \\
\hline Writing letters with your feet in the air & 13 & 65 \\
\hline
\end{tabular}

The intensity and the total daily time experiencing pain(TDTEP) of PLP significantly decreased after training mirror exercises in both groups of patients with PLP and PLS (Table 4). The extent of drug use also decreased up to 'no use' in patients with PLP and to a rather small extent in patients with PLS ( $\mathrm{p}<0.05$ Table 4). The results was still kept maintenance or improved (Table 3) after finishing the therapy program. Depression scores also decreased after treatment and continued to decline ( $p<0,001$ Table 5). The study results did not find a statistical significance relationship between the effect of reducing the intensity, duration of PLPh, depression score CESD with factors such as age, gender, cause of amputation, degree of amputation with p-values $>0.05$ (Table 5). We did not find the relationship between pain and depression improvement with the factors such as age, gender, cause of amputation, level of amputation (Table 6). 
Table 3: PLPh results at the time end of study $(n=20)$.

\begin{tabular}{|c|c|c|c|c|c|c|}
\hline & \multicolumn{3}{|c|}{ PLP (n=11) } & PLS (n=9) \\
\hline & $\begin{array}{c}\text { Finishing Mirror } \\
\text { Treatment }\end{array}$ & End of Study & P-value & $\begin{array}{c}\text { Finishing Mirror } \\
\text { Treatment }\end{array}$ & End of Study & P-value \\
\hline VAS & $1(0-2)$ & $0(0-1)$ & $0,030^{\mathrm{a}}$ & $2(1-3)$ & $1(1-3)$ & $0,317^{\mathrm{a}}$ \\
\hline $\begin{array}{c}\text { PLPh Duration/ } \\
\text { Days }\end{array}$ & $10(5-15)$ & $0(0-1)$ & $0,005^{\mathrm{a}}$ & $15(5-40)$ & $6(1-45)$ & $0,094^{\mathrm{a}}$ \\
\hline \multicolumn{7}{|c|}{ Using Pain Relievers n (\%) } \\
\hline No & $11(100)$ & $11(100)$ & $1,000^{\mathrm{b}}$ & $7(77,8)$ & $9(100)$ & $0,471^{\mathrm{b}}$ \\
\hline Yes & $0(0)$ & $0(0)$ & & $2(22,2)$ & $0(0)$ & \\
\hline
\end{tabular}

Table 4: PLPh results at the time of finishing mirror training $(n=20)$.

\begin{tabular}{|c|c|c|c|c|c|c|}
\hline & \multicolumn{7}{|c|}{ PLP(n=11) } & \multicolumn{2}{c|}{ PLS (n=9) } \\
\hline & $\begin{array}{c}\text { Before Mirror } \\
\text { Treatment }\end{array}$ & $\begin{array}{c}\text { Finishing Mirror } \\
\text { Treatment }\end{array}$ & P-value & $\begin{array}{c}\text { Before Mirror } \\
\text { Treatment }\end{array}$ & $\begin{array}{c}\text { Finishing Mirror } \\
\text { Treatment }\end{array}$ & P-value \\
\hline VAS & $4(4-5)$ & $1(0-2)$ & $0,003^{\mathrm{a}}$ & $5(3-5)$ & $2(1-3)$ & $0,012 \mathrm{a}$ \\
\hline $\begin{array}{c}\text { PLPh Duration/ } \\
\text { Days (minutes) }\end{array}$ & $150(105-240)$ & $10(5-15)$ & $0,003^{\mathrm{a}}$ & $450(80-450)$ & $15(5-40)$ & $0,009 \mathrm{a}$ \\
\hline \multicolumn{7}{|c|}{ Using Analgesic n (\%) } \\
\hline No & $1(9,1)$ & $11(100)$ & $<0,001^{\mathrm{b}}$ & $1(11,1)$ & $7(77,8)$ & $0,015 \mathrm{~b}$ \\
\hline Yes & $10(90,9)$ & $0(0)$ & & $8(88,9)$ & $2(22,2)$ & \\
\hline
\end{tabular}

Table 5: The results of depression after mirror treatment $(n=20)$.

\begin{tabular}{|c|c|c|c|c|c|}
\hline & $\begin{array}{l}\text { Before Mirror } \\
\text { Treatment }\end{array}$ & $\begin{array}{l}\text { Finishing Mirror } \\
\text { Treatment }\end{array}$ & End of Study & $\begin{array}{l}\text { P (Comparison } \\
\text { between Before and } \\
\text { Finishing Mirror } \\
\text { Training) }\end{array}$ & $\begin{array}{c}\text { P (Comparison } \\
\text { between Finishing } \\
\text { Mirror Training End } \\
\text { of Study) }\end{array}$ \\
\hline CES-D & $17(14-24,5)$ & $8(4-12,5)$ & $4,5(2,5-10)$ & $<0,001^{a}$ & $<0,001^{\mathrm{a}}$ \\
\hline \multicolumn{6}{|c|}{ Depression - n (\%) } \\
\hline No & $7(35,0)$ & $18(90,0)$ & $19(95,0)$ & $<0,001^{\mathrm{c}}$ & $1,000^{\mathrm{b}}$ \\
\hline Yes & $13(65,0)$ & $2(10,0)$ & $1(5,0)$ & & \\
\hline
\end{tabular}

${ }^{\mathrm{a} A c c r e d i t}$ Wilcoxon signed-rank, ${ }^{\mathrm{b}}$ Accredit Fisher, ${ }^{\mathrm{c} A c c r e d i t}$ Chi square.

Table 6: The relation between improved difference PLPh, CESD and other factors $(n=20)$.

\begin{tabular}{|c|c|c|c|c|c|c|c|c|c|c|}
\hline & \multicolumn{4}{|c|}{ PLP } & \multicolumn{4}{|c|}{ PLS } & \multirow{2}{*}{\multicolumn{2}{|c|}{ CESD }} \\
\hline & \multicolumn{2}{|c|}{ PLP Intensity } & \multicolumn{2}{|c|}{ PLP Duration } & \multicolumn{2}{|c|}{ PLS Intensity } & \multicolumn{2}{|c|}{ PLS Duration } & & \\
\hline & Difference & $\mathbf{p}$ & Difference & $\mathbf{P}$ & Difference & $\mathbf{p}$ & Difference & $\mathbf{p}$ & Difference & $\mathbf{p}$ \\
\hline \multicolumn{11}{|c|}{ Group Age } \\
\hline 18-34 years old & $4(4-4)$ & 0,216 & $150(104-150)$ & 0,476 & $5(5-5)$ & 0,117 & $450(450-450)$ & 0,245 & $14(13-17)$ & 0,240 \\
\hline$\geq 35$ years old & $3,5(3-4)$ & & $245(140-350)$ & & $2,5(0,5-3,5)$ & & $212(32-444,5)$ & & $10(3-15)$ & \\
\hline \multicolumn{11}{|c|}{ Gender } \\
\hline Male & $4(3-4)$ & - & $150(104-240)$ & - & $3(1-4)$ & 0,296 & $250(35-450)$ & 0,380 & $13,5(7-17)$ & 0,569 \\
\hline Female & & & & & $2(0-4)$ & & $210(-20-440)$ & & $9(3-15)$ & \\
\hline \multicolumn{11}{|c|}{ Causes Leading to Amputation } \\
\hline Trauma & $4(4-4)$ & & $145(104-150)$ & & $3,5(1-4)$ & & $445(250-450)$ & & $13,5(8-16,5)$ & \\
\hline Other & $4(4-4)$ & 1,000 & $350(350-350)$ & 0,202 & $2(0-3)$ & 1,000 & $35(29-174)$ & 0,121 & $8,5(2,5-18)$ & 0,477 \\
\hline \multicolumn{11}{|c|}{ Amputation Level } \\
\hline Below knee & $4(4-4)$ & & $104(89-150)$ & & $2,5(0-3)$ & & $104,5(29-449)$ & & $14(3-17)$ & \\
\hline $\begin{array}{c}\text { From the knee and } \\
\text { above }\end{array}$ & $4(3-4)$ & 0,056 & $195(140-350)$ & 0,065 & $4(1-5)$ & 0,239 & $440(250-450)$ & 0,302 & $13(7-15)$ & 0,970 \\
\hline
\end{tabular}




\begin{tabular}{|c|c|c|c|c|c|c|c|c|c|c|}
\hline \multicolumn{11}{|c|}{ Favourite Exercises } \\
\hline$<11$ exercises & $4(4-4)$ & 1,000 & $150(89-350)$ & 0,854 & $2,5(0,5-3,5)$ & 0,117 & $212(32-444,5)$ & 0,245 & $13(5-15)$ & 0,450 \\
\hline 11 exercises & $3(4-4)$ & & $145(120-150)$ & & $5(5-5)$ & & $450(450-450)$ & & $14(7-18)$ & \\
\hline \multicolumn{11}{|c|}{ PLPh } \\
\hline PLP & & & & & & & & & $14(9-17)$ & 0,381 \\
\hline PLS & & & & & & & & & $13(3-15)$ & \\
\hline
\end{tabular}

\section{Discussion}

Post-amputation phantom limb pain (PLP) is highly prevalent and might be very difficult to treat. The high-prevalence, high-pain intensity levels, and decreased quality of life associated with PLP compel scientists to find out the ways to prevent, manage, and reverse this chronic pain condition. Currently, Nonoperative and non-drug PLP interventions include targeted muscle reinnervation (TMR), repetitive transcranial magnetic stimulation (rTMS), imaginal phantom limb exercises, mirror therapy (MT), virtual and augmented reality, and eye movement desensitization and reprocessing (EMDR) therapy. They are reported to be effective , however, no one is widely accepted or clearly superior to the others. Moreover, not one intervention has been found to be consistently effective [16]. Mirror therapy seems to be an suitable way for developing countries with their high rate of amputation because mirror could be available with low cost in anywhere. Mirror therapy is expected to be widely used for the treatment of phantom limb pain since it is easy to use at both home and in outpatient departments.

There are many theories to explain the mechanism of mirror therapy. Despite how the therapy has effect on central nervous system and reduce pain, one of the most important keys for success is the patient's adherence. It is much easy to strictly follow the treatment program if the program includes simple and feasible exercises. It is also more significant if the patients experience the exercises at least one time and that makes them comfortable. That is the reason why we built a set of exercises basing on the patient's preference. To our knowledge few study have similar treatment approach. Our encouraging results reinforce the previous studies in which mirror therapy reduced PLP in lower extremity amputees [9-11,16]. However, the "rebound phenomenon" after stopping practicing mirror exercises might be a big concern. In order to evaluate the stability of the effectiveness we still followed up our patients for about 4 months. We found that the intensity and TDTEP of PLPh continued to decrease. We also found some accompanying positive effects such as the decrease of the demand of pain killer and improvement of depression condition. The Darnall BD study also gave similar results [10].

\section{Conclusion}

Home based Four- week practice of mirror therapy with an individual set of exercises based on the patient's result in significant reduction of PLP and PLPh and their improvement of depression condition in lower limb amputees. The interventions are simple and cost- benefit thus appropriate to the low-resource communities.

\section{Conflict of Interest}

Each author certifies that he or she has no commercial associations (e.g, consultancies, stock ownership, equity interest, patent/licensing arrangements, etc.) that might pose a conflict of interest in connection with the submitted article.

\section{Ethical Approval}

The study was approved by the Ethics Committee in Biomedical Research, University of Medicine and Pharmacy, Ho Chi Minh City. Ho Chi Minh City number: 58/HDDD on January 13, 2020.The authors certify that the conducted institution approved the protocol of this investigation and that all investigations were conducted in conformity with ethical principles of research.

\section{References}

1. Mishra A (2014) Lower Limb Amputations, Conference: Surgery Update 2014 at New Delhi, India, p. 1-2.

2. Ajibade A, Akinniyi OT, Okoye CS (2013) Indications and complications of major limb amputations in Kano, Nigeria. Ghana Med J 47(4): 185188.

3. Keil G (1990) So-called initial description of phantom pain by Ambroise Paré. "Chose digne d'admiration et quasi incredible": the "douleur ès parties mortes et amputées". Fortschr Med 108(4): 62-66.

4. Padovani MT, Martins MR, Venancio A, JEN (2015) Anxiety, depression and quality of life in individuals with phantom limb pain. Acta Ortop Bras 23(2): 107-110.

5. Jaeger H, Maier C (1992) Calcitonin in phantom limb pain: a doubleblind study. Pain 48(1): 21-27.

6. Sherman RA, Sherman CJ (1983) Prevalence and characteristics of chronic phantom limb pain among American veterans. Results of a trial survey. Am J Phys Med 62(5): 227-238.

7. Sin EI, Thong SY, Poon KH (2013) Incidence of phantom limb phenomena after lower limb amputations in a Singapore tertiary hospital. Singapore Med J 54(2): 75-81.

8. Ramachandran VS, Rogers Ramachandran D (1996) Synaesthesia in phantom limbs induced with mirrors. Proc Biol Sci 263(1369): 377-386.

9. Chan BL, Witt R, Charrow AP, Magee A, Howard R, et al. (2007) Mirror therapy for phantom limb pain. N Engl J Med 357(21): 2206-2207.

10. Darnall BD, Li H (2012) Home-based self-delivered mirror therapy for phantom pain: a pilot study. Journal of Rehabilitation Medicine 44(3): 254-260. 
11. Yildirim M, Kanan N (2016) The effect of mirror therapy on the management of phantom limb pain. Agri 28(3): 127-134.

12. Rothgangel A, Braun S, de Witte L, et al (2016) Development of a Clinical Framework for Mirror Therapy in Patients with Phantom Limb Pain: An Evidence-based Practice Approach. Pain Pract 16(4): 422-434.

13. Bô Y Tế (2017) Guidelines for technical rehabilitation procedures (Phase 2). Hanoi Medical Publishing House, Hanoi, pp. 180-182.

14. Brodie EE, Whyte A, Niven CA (2007) Analgesia through the lookingglass? A randomized controlled trial investigating the effect of viewing

\section{ISSN: 2574-1241}

DOI: 10.26717/BJSTR.2021.37.005967

Hung Do Phuoc. Biomed J Sci \& Tech Res

(C) This work is licensed under Creative

Submission Link: https://biomedres.us/submit-manuscript.php a 'virtual' limb upon phantom limb pain, sensation and movement. Eur J Pain 11(4): 428-436

15. Sumitani M, Miyauchi S, McCabe CS, Shibata M, Maeda L, et al. (2008) Mirror visual feedback alleviates deafferentation pain, depending on qualitative aspects of the pain: a preliminary report. Rheumatology (Oxford) 47(7): 1038-1043.

16. Finn SB, Perry Briana, N, Clasing Jay E, Walters LS, Jarzombek SL, et al. (2017) A Randomized, Controlled Trial of Mirror Therapy for Upper Extremity Phantom Limb Pain in Male Amputees. Frontiers in Neurology 8: 267. 